\title{
SPECIAL ASPECTS OF THE DEVELOPMENT OF HEALTH INFORMATION SYSTEMS AS ONE OF THE AREAS OF EXPERTISE OF UNIVERSITY STUDENTS MAJORING IN PROFESSIONAL INSTRUMENT ENGINEERING
}

\author{
Elena Vaganova* \\ National Research Tomsk State University, 634050, Tomsk, Russia
}

\begin{abstract}
The article describes distinguishing features of development and production economics of health information systems. Characteristics of medicine as a subject area from the point of view of developers are presented. Basics of medical informatics and the special aspects of development of medical products are proposed to be one of the areas of expertise of university students majoring in professional instrument engineering.
\end{abstract}

\section{Introduction}

Health information systems (HIS) - a set of software, hardware, and data and knowledge bases for automation of health care processes in medical and prophylactic institutions. The market of health (healthcare, hospital) information systems (HIS) was initiated in 1960s, when they were used primarily for hospital inventory. Nowadays HIS are included in the integration of all clinical, financial and administrative processes. Modern HIS consist of multiple applications, meeting the needs of different departments in a hospital. Hospitals using HIS have access to a fast and reliable data, including patient records (demographics, gender, age and others) [1-3].

\section{Special aspects of the development of health information systems}

Medicine has made a significant progress in the diagnosis and treatment of many diseases, involving more and more technically advanced tools and methods. HIS meets the needs of the medical and management personnel in the arrangement of information used for improvement of healthcare and decision-making [4]. Besides the primary objective a corporate HIS carries out the following tasks:

- common information space, intended for immediate access to information;

- improving the quality of medical records;

\footnotetext{
Corresponding author: hailun@mail.ru
} 
- control of health care quality, and as a result, reduction of probability of medical errors;

- increasing the transparency of a medical institution;

- analysis of the economic aspects of health care;

- deducing the time of examination and treatment.

HIS of a medical center provides a single information space, where doctors, nurses, hospital administrators work closely with each other. The control process is performed my means of multimedia data, including texts, images, numerical values, and so on, providing comprehensive solutions of control problems. Complexity and ambiguity of the subject area include responsibility for other people's health. Thus main feature of medical informatics is each HIS should be developed precisely in terms of conditions in which it will be operated.

The developers of health information systems have to deal with a constantly changing subject area. The most important sources of these changes are:

- development of social and economic spheres;

- development of medical science;

- the influence of information technologies on patients' behavior (they become more informed) and health management in general.

Before developing a HIS a number of important issues must be considered:

- Detailed analysis of the structure of the organization and collaborative mechanisms between the participants of internal and external processes.

- Planning software and hardware tools and resources necessary for the development and operation of the system.

- Detailed calculation of the resources necessary for the development and maintenance of the system.

- Information awareness regarding the software systems used previously.

The object of medicine is a human being. The subjects of the medicine are etiology, pathogenesis, diagnostics, treatment, and prevention of diseases. The complexity of medicine as a field of human activity is reflected in management of health care institutions and in the development and operation of HIS.

Medicine has made a significant progress in the diagnosis and treatment of many diseases, involving more and more technically advanced tools and methods. All the complexity of medicine includes such issues as management of medical institutions and the of development and implementation of medical information systems. The developers of health information systems have to deal with a constantly changing subject area. The most important sources of these changes are:

- development of social and economic spheres;

- development of medical science;

- the influence of information technologies on patients' behavior (they become more informed) and health management in general.

Another special feature of health information is privacy. In Russia the rights of citizens for confidentiality of health encounters are protected by Federal laws regarding health care [5].

\section{Understanding principles of the development of health information systems as one of the educational competencies}

Creation of complex software products, including HIS, by large groups of experts requires efficient production management, planning of costs and deadlines. The developers of complex software systems, as a rule, do not know the basics of economic issues of 
industrial production of complex technical products, and managers do not understand completely properties of objects developed, as well as special features of technological processes. This complicates the implementation process as well. Thus, basic knowledge of the specifics of the development of medical products should be considered as one of the competencies of future engineers.

Competency-based approach, applied in basic educational programs of engineering majors, must take into account constant changes in the labor market. Occupational activities of graduates of basic educational programs majoring in engineering consist of research and development, design and engineering, production and technology, and management. Research and development activity can include basic principles of the development of health information systems and the characteristics of medical informatics. For one of the competencies of production and technological activity of design engineers include the understanding of the principles of the development of health information systems and the characteristics of medical informatics [6].

\section{Conclusion}

In higher education of the Russian Federation a lot has been done in recent years to implement competency-based approach to studies (knowledge, skills). The number of educational programs for undergraduate and graduate students majoring in engineering is constantly growing.

Russia is a comparatively young participant in the market discovering the achievements of heath informatics, reproduction and restoration of human resources on the basis of new technologies.

Due to the fact that in recent years, in Russia a growing number of health information systems for automation of health care institutions have been developed and implemented $[7,8]$, basics of medical informatics, including specifics of the development of medical devices should be included in educational programs of engineering majors.

\section{Acknowledgement}

The study was performed within the framework of the Agreement № 14.579.21.0019 (unique identifier for the project - RFMEFI57914X0019) on the «Development of the device for daily monitoring of the fetus and the mother during pregnancy by controlling the parameters of the cardiovascular system based on the acoustic data», signed between the R\&D company «Diagnostika+» LLC and the Ministry of Education and Science of the Russian Federation, and the program of improving competitiveness of the TSU (project No. 8.2.31.2015).

\section{References}

[1] R. Haux, International journal of medical informatics 79, 599 (2010)

[2] N. S. Fleming, S. D. Culler, R. Mccorkle, E. R. Becker, D. J. Ballard, Health Affairs 30,481 (2011)

[3] R. Hillestad, J. Bigelow, A. Bower, F. Girosi, R.Meili, R. Scoville and R. Taylor, Health Affairs 24,1103 (2005)

[4] M. Ngafeeson, Healthcare Information Systems: Opportunities and Challenges (IGI Global, Hershey, 2014) 
[5] Ya. I. Guliev, I. F. Gulieva, E. V. Rjumina, O. A. Foht, Je. F. Tavlybaev, A. Ju. Programmnye sistemy: teorija i prilozhenija 4, 3 (2012)

[6] S.L. Eremina M.D. Gladkova Tomsk State University Journal of Economics 3 , 187 (2013)

[7] E. V. Vaganova M. V. Syryamkin, AIP Conference Proceedings 1688, 040012 (2015)

[8] V.I. Syryamkin, A.S. Bureev, D.S.Zhdanov, A.V. Osipov, S.A. Klestov, Biomedical Engineering 46, 112 (2012) doi: 10.1007/s10527-012-9281-X 